\title{
Functional capacity of reconstituted blood in 1:1:1 versus 3:1:1 ratios: A thrombelastometry study
}

\author{
Arne Driessen ${ }^{1,2 \dagger}$, Nadine Schäfer ${ }^{1 \dagger}$, Ursula Bauerfeind ${ }^{3}$, Sigune Kaske ${ }^{2}$, Carolin Fromm-Dornieden ${ }^{1}$, \\ Ewa K Stuermer ${ }^{1}$ and Marc Maegele $2^{2^{*}}$
}

\begin{abstract}
Introduction: Different transfusion ratio concepts of packed red blood cells (pRBCs), fresh frozen plasma (FFP) and platelets (PLTs) have been implemented in trauma care, but the optimal ratios are still discussed. In this study the hemostatic potential of two predefined ratios was assessed by using an in vitro thrombelastometric approach. Furthermore, age effects of reconstituted blood were analyzed.

Methods: Whole blood (WB) of voluntary donors was separated into pRBCs, FFP and PLTs and reconstituted into the ratios 1:1:1 and 3:1:1 at day 1,4,14, and 24. Standard blood count, electrolytes and coagulation proteins were quantified. The functional coagulation in ratio- and age-specific groups was evaluated using rotational thromboelastometry (ROTEM).

Results: Several coagulation factors reduced significantly in the 3:1:1 ratio and were consistent with increased INR, decelerated clot formation times and A10 (amplitude 10 minutes after clotting time (CT)), flattened a-angle during the EXTEM and diminished MCF for distinct time points during the INTEM, FIBTEM and APTEM assays. With rising age of pRBCs the $\mathrm{pH}$, sodium and potassium reached non-physiological levels.

Conclusion: Under standardized in vitro conditions the higher amount of pRBCs in the 3:1:1 ratio diluted coagulation factors significantly on the expense of its functional coagulation capacity as revealed by ROTEM results. Thus, the coagulation functionality of the 1:1:1 ratio predominated.
\end{abstract}

Keywords: Transfusion practices, Acute bleeding injury, Coagulopathy, Thrombelastometry in trauma, Ratio of components

\section{Introduction}

As there is less doubt about the components to be administered during transfusion the evidence for an appropriate transfusion ratio is still lacking [1]. Different ratios of pRBCs, FFP and PLTs are applied in clinical practice [2-4] at which the 1:1:1 ratio has been adopted by trauma centers worldwide for the acute treatment of bleeding trauma patients [5,6]. For massive transfusion the use of a RBC:FFP ratio of 1:1 or 2:1 was recommended based on systematic reviews [7-11] and a reduction of death risk for trauma patients was associated

\footnotetext{
* Correspondence: marc.maegele@t-online.de

${ }^{\dagger}$ Equal contributors

2Department of Traumatology, Orthopaedic Surgery and Sports

Traumatology, Cologne-Merheim Medical Centre (CMMC), Witten/Herdecke University, Campus Cologne-Merheim, Ostmerheimer Str. 200, D-51109

Cologne, Germany

Full list of author information is available at the end of the article
}

when transfused in the range of $1: 1$ to $2.5: 1$. Currently, the PROPPR study as a phase III prospective randomized trial was conducted by several trauma centers in the United States that targets the efficacy of the transfusion ratio 1:1:1 compared to 2:1:1 (pRBCs:FFP:PLTs) within a massive transfusion (MT). Overall limited evidence due to retrospective or unfinished prospective designs [12] and numerous potential confounders $[1,10,13-16]$ as well as poor compliance to MT protocols (MTP) during resuscitation limits the expressiveness and results of these studies.

Besides transfusion ratios the application of blood products stored less than two weeks (fresh blood) or more than 14 days (old blood) is also crucially discussed. Previously, lower postoperative complications and increased long-term survival were observed after cardiac surgery when transfusing fresh compared to older blood 
$[17,18]$. A higher mortality rate and severity of transfusion related acute lung injury (TRALI) was shown after administering stored $\mathrm{pRBC}$ in different animal studies $[18,19]$ with comparable results in additional studies [20-24]. Furthermore the erythrocyte cell membrane deformability irreversibly decreased with storage duration and might be responsible for reduced oxygen transport [24-29].

The present study addressed the question of a predominance of the ratios 1:1:1 and 3:1:1 of pRBCs, FFP and PLTs in contrast to whole blood on the one hand and age-specificities of fresh and old blood on the other. For this purpose, they were compared in vitro under standardized conditions by measuring electrolytes, blood and coagulation proteins as well as analyzing functionality of coagulation and at distinct time points.

\section{Methods}

\section{Blood donation and further processing}

After institutional review board approval and written informed consent a volume of $450 \mathrm{ml}$ type A blood of six voluntary donors was collected in standard bags supplemented with $63 \mathrm{ml}$ of CPD (citrate, phosphate, dextrose) stabilization solution. Initially, the blood was stored for 20 hours at validated CompoCool plates (Fresenius Kabi, Bad Homburg, Germany) prior to leukocyte-depletion (by filtering) and separation (by centrifugation) into pRBCs, FFP and PLTs. The pRBC of $260 \pm 50 \mathrm{ml}$ volume contained $100 \mathrm{ml}$ of SAG-M (adenine, glucose and mannitol) solution and were stored at $4^{\circ} \mathrm{C} \pm 2^{\circ} \mathrm{C}$ until usage. FFP was portioned in $250 \pm 30 \mathrm{ml}$ bags, shock-frozen and stored at $-30^{\circ} \mathrm{C}$. Due to the short storage life a maximum four days old PLTs bag of $260 \pm 40 \mathrm{ml}$ was used that had been incubated under constant agitation at $22^{\circ} \mathrm{C} \pm 2^{\circ} \mathrm{C}$.

Since the volume of the blood product bags differed, the pRBCs, FFPs and PLTs were weighted first before calculating its percentage of volume prior reconstitution which allowed a realistic transfusion procedure of the ratios 1:1:1 and 3:1:1 to a final volume of $50 \mathrm{ml}$. All measurements were performed at day one, four, 14, and 24 . Additionally, whole blood was measured at day one. The detailed proceeding was represented in Figure 1.

\section{Measurement of blood parameters}

All measurements were performed at the Institute of Transfusion Medicine, Cologne-Merheim Medical Centre. The standard hemogram (Full Blood Count, FBC) parameters erythrocytes, leucocytes, platelets, hemoglobin, hematocrit, mean corpuscular volume $(\mathrm{MCV})$, mean corpuscular hemoglobin $(\mathrm{MCH})$, mean corpuscular hemoglobin concentration (MCHC), and red blood cell distribution width (RDW) were measured on the CellDyn 1700 Hematology Analyzer (Abbott Laboratories, Abbott Park, USA). International normalized ratio (INR), partial thromboplastin time (PTT), fibrinogen, antithrombin, the factors II, V, VII, VIII, IX, X, XI, XII, and VIII, protein $\mathrm{C}$, protein $\mathrm{S}$, d-dimer, vonWillebrand factor activity (vWF:a), and vonWillebrand factor Antigen (vWF:Ag) were quantified following the manufacturer's manuals (Instrumentation Laboratory Company; Bedford, USA; Siemens Healthcare Diagnostics Products GmbH, Marburg, Germany) by using the ACL TOP system (Instrumentation Laboratory Company; Bedford, USA) and the APACT $4 S$ Plus (Rolf Greiner BioChemica, Flacht, Germany).

The values of sodium, potassium, calcium, and the $\mathrm{pH}$ were determined by blood gas analysis via the IRMA TruPoint Blood Analysis System (Keller Medical GmbH, Bad Soden, Germany).

\section{ROTEM $^{\circledR}$ analysis}

Kinetics of hemostasis was followed by ROTEM delta analysis in accordance to the manufacturer's instructions (Tem International GmbH, Munich, Germany) (Figure 2). The 30 minutes thromboelastometric measurement included the extrinsically activated assay with tissue factor (EXTEM), the intrinsically activated test using ellagic acid (INTEM), the extrinsically activated test with tissue factor

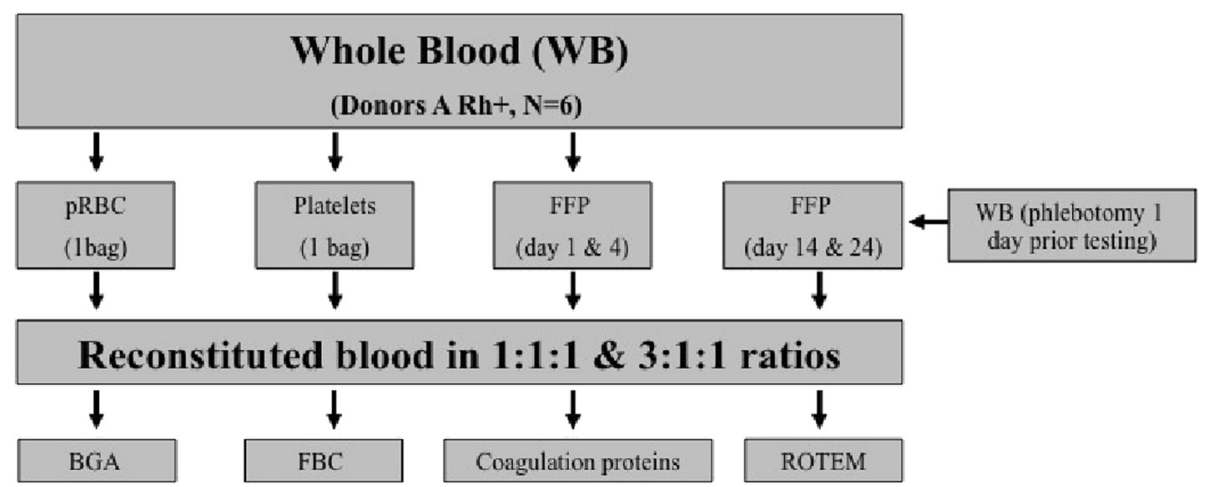

Figure 1 Procedure of blood separation and reconstitution as well as subsequent experiments. 


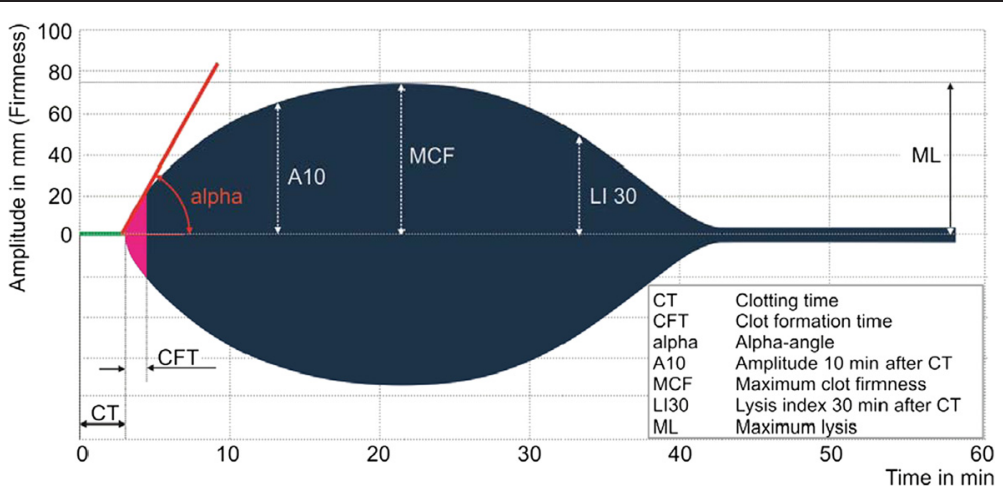

Figure 2 Kinetics of hemostasis as demonstrated by a viscoelastic test (ROTEM, Tem Innovations GmbH).

and the platelet inhibitor cytochalasin D (FIBTEM) as well as the extrinsically activated assay after blocking hyperfibrinolysis by aprotinin (APTEM). The parameters clotting time (CT), clot formation time (CFT), $\alpha$-angle, amplitude 10 minutes after CT (A10), and maximal clot firmness (MCF) were analyzed for the EXTEM, INTEM and APTEM assays while the CFT was not determined for FIBTEM.

\section{Statistics}

Collected data were analyzed by the nonparametric Kruskal-Wallis test to assess the effects of time and ratio in the different time-by-ratio groups using the IBM SPSS Statistics, version 21.0 (Armonk, NY, USA). $P$ values were corrected in the subsequent pairwise comparison of groups. Differences were considered statistically significant at $p<0.05$.

The cumulative comparison of coagulation factor activity was performed by calculating the overall mean of all factors for the WB, 1:1:1 and 3:1:1 group, respectively.

\section{Results}

\section{Blood count and electrolytes}

Irrespective of blood product age, several measured parameters differed between the ratios $1: 1: 1$ and $3: 1: 1$ (Table 1). The quantity of erythrocytes was significantly lower in the 1:1:1 group compared to WB. Platelets were elevated in the 1:1:1 ratio at all points in time and differed significantly from the corresponding levels of the whole blood. Leucocyte depletion of the original blood samples resulted in a drastically decline in both ratios $(<500 / \mu \mathrm{l})$. While hemoglobin and hematocrit levels of the 3:1:1 ratio and the WB were likewise, the 1:1:1 ratio had significantly reduced levels in comparison with both groups at the reviewed time points. Overall, age-specific differences were not observed for erythrocytes, platelets, hemoglobin, and hematocrit. Similarly, MCV, MCH and RDW remained constant and were not affected by age or ratio.

Only few age effects could be observed (Table 2) and thereof most notably the values of potassium and sodium. Independent of ratio potassium increased progressively over time being 2.4- and 4.6-fold higher after 24 days in the 1:1:1 and 3:1:1 ratio, respectively. In contrast, sodium reduced with increasing age and differed significantly in both ratios between day one and 24 . The environment of the reconstituted blood slightly acidified as in both ratios the $\mathrm{pH}$ value decreased with age and was reduced stronger in the 3:1:1 group from day four (Table 2). No alteration of calcium was determined during the measurement.

\section{Coagulation proteins}

For almost all coagulation factors ratio-specific reductions in the 3:1:1 group were observed at any time point when comparing both ratios (Table 1). The factors VII, IX, $\mathrm{X}$ and XII were constantly and significantly reduced in 3:1:1 samples, independent of age while the factors II, $\mathrm{V}$, and XIII significantly declined not before day four. Similar to the blood count parameter the quantity of coagulation factors was affected minor by age (Table 2). Although several factors tended to be reduced after 24 days only the factors II, V and VII measured in the 1:1:1 ratio and factors IX, XI and XIII in the 3:1:1 group reached the level of significance. The cumulative factors were comparable in the WB and 1:1:1 group whereas a precise decline was observed when comparing both groups to the 3:1:1 ratio at day 1 or when comparing the 1:1:1 with the 3:1:1 ratio at the respective time points (Figure 3).

The activity of the coagulation inhibitors antithrombin and protein $\mathrm{C}$ as well as its cofactor protein $\mathrm{S}$ were significantly lowered in the 3:1:1 compared to WB (day one) and in most cases considerably reduced in 1:1:1 ratio at all ages (Table 2). Fibrinogen was also diluted in 3:1:1 samples from day four on (Table 1).

\section{Functionality of coagulation}

Consistent with the reduction of coagulation proteins in the 3:1:1 ratio an elevated PTT and INR were observed in the 1:1:1 group irrespective of age. Both values 
Table 1 Significant ratio-specific differences of the ratios 1:1:1 and 3:1:1

\begin{tabular}{|c|c|c|c|c|c|c|c|c|c|}
\hline \multirow[t]{2}{*}{ Parameter } & \multicolumn{3}{|l|}{ Day 1} & \multicolumn{2}{|l|}{ Day 4} & \multicolumn{2}{|l|}{ Day 14} & \multicolumn{2}{|l|}{ Day 24} \\
\hline & WB & 1:1:1 & 3:1:1 & $1: 1: 1$ & 3:1:1 & 1:1:1 & 3:1:1 & $1: 1: 1$ & 3:1:1 \\
\hline Erythrocytes $\left[\times 10^{6} / \mu l\right]$ & $3.79 \pm 0.29$ & $2.14 \pm 0.54^{+}$ & $3.65 \pm 0.85$ & $2.01 \pm 0.14^{*}$ & $3.68 \pm 0.29$ & $1.96 \pm 0.13^{*}$ & $3.3 \pm 0.34$ & $2.09 \pm 0.64^{*}$ & $3.08 \pm 0.61$ \\
\hline Leukocytes $\left[\times 10^{3} / \mu 1\right]$ & $6.55 \pm 2.05$ & $0.25 \pm 0.05^{+}$ & $0.33 \pm 0.1^{+}$ & $0.37 \pm 0.08$ & $0.33 \pm 0.14$ & $0.35 \pm 0.1$ & $0.25 \pm 0.08$ & $0.45 \pm 0.1$ & $0.5 \pm 0.18$ \\
\hline Platelets $\left[\times 10^{3} / \mu l\right]$ & $236.5 \pm 43.1$ & $348.5 \pm 36.39^{+, *}$ & $226.5 \pm 28.51$ & $327.5 \pm 22.42^{*}$ & $181 \pm 44.09$ & $359.17 \pm 20.68^{*}$ & $231.5 \pm 38.83$ & $334.83 \pm 37.5^{*}$ & $231.5 \pm 58.11$ \\
\hline Hemoglobin [g/dl] & $11.78 \pm 1.11$ & $6.6 \pm 1.67^{+, *}$ & $11.43 \pm 2.54$ & $6.2 \pm 0.56^{*}$ & $11.42 \pm 1.08$ & $6.12 \pm 0.5^{*}$ & $10.38 \pm 1.25$ & $6.47 \pm 2.27^{*}$ & $9.76 \pm 1.71$ \\
\hline Hematocrit [\%] & $37.08 \pm 3.21$ & $20.85 \pm 4.29^{+, *}$ & $35.7 \pm 7.14$ & $20.27 \pm 1.55^{*}$ & $37.13 \pm 3.19$ & $19.5 \pm 1.76^{*}$ & $32.97 \pm 3.88$ & $21.33 \pm 7.26$ & $30.92 \pm 5.29$ \\
\hline $\mathrm{MCHC}[\mathrm{g} / \mathrm{dl}]$ & $31.75 \pm 0.7$ & $31.47 \pm 1.27$ & $31.9 \pm 0.65$ & $30.57 \pm 0.6$ & $30.72 \pm 0.5$ & $30.75 \pm 0.18^{*}$ & $31.5 \pm 0.64$ & $30.25 \pm 0.49$ & $30.83 \pm 0.7$ \\
\hline $\mathrm{pH}$ & $6.92 \pm 0.06$ & $7.04 \pm 0.04^{+}$ & $6.95 \pm 0.05$ & $7.03 \pm 0.05^{*}$ & $6.9 \pm 0.04$ & $6.91 \pm 0.08^{*}$ & $6.76 \pm 0.03$ & $6.89 \pm 0.03^{*}$ & $6.69 \pm 0.06$ \\
\hline Sodium [mM] & $139.67 \pm 2.33$ & $142.62 \pm 6.15$ & $145.37 \pm 5.14$ & $140.48 \pm 1.63^{*}$ & $142.3 \pm 0.89$ & $138.67 \pm 0.81$ & $138.43 \pm 2.09$ & $137.42 \pm 0.99$ & $136.72 \pm 1.67$ \\
\hline Potassium [mM] & $3.33 \pm 0.4$ & $3.12 \pm 0.38$ & $2.83 \pm 0.78$ & $3.91 \pm 0.38^{*}$ & $4.69 \pm 0.35$ & $6.72 \pm 1.3^{*}$ & $9.19 \pm 0.95$ & $7.45 \pm 0.48^{*}$ & $13.01 \pm 0.15$ \\
\hline EXTEM CFT [s] & $101.83 \pm 49.17$ & $59.83 \pm 10.94^{*}$ & $125.33 \pm 27.5$ & $54.83 \pm 5.49^{*}$ & $127.67 \pm 50.71$ & $59.33 \pm 16.46^{*}$ & $139.5 \pm 46.87$ & $74.33 \pm 27.98$ & $99.5 \pm 34.81$ \\
\hline INTEM CFT [s] & $133.5 \pm 67.16$ & $70.33 \pm 24.83$ & $144.17 \pm 99.03$ & $55.5 \pm 6.8^{*}$ & $119.5 \pm 39.51$ & $114.17 \pm 94.2$ & $166.5 \pm 78.58$ & $67 \pm 34.48$ & $92.5 \pm 18.17$ \\
\hline APTEM CFT [s] & $119.17 \pm 74.34$ & $72.67 \pm 22.81$ & $108 \pm 33.89$ & $70.5 \pm 16.88^{*}$ & $131.33 \pm 57.6$ & $66.83 \pm 19.06^{*}$ & $133.5 \pm 44.28$ & $65.33 \pm 30.74$ & $84.33 \pm 19.31$ \\
\hline INR & $1.12 \pm 0.1$ & $1.03 \pm 0.05^{*}$ & $1.23 \pm 0.08$ & $1.13 \pm 0.05^{*}$ & $1.52 \pm 0.25$ & $1.12 \pm 0.04^{*}$ & $1.53 \pm 0.15$ & $1.17 \pm 0.08^{*}$ & $1.45 \pm 0.14$ \\
\hline PTा [s] & $38.33 \pm 4.59$ & $33.67 \pm 3.83$ & $36.83 \pm 5.49$ & $33.83 \pm 2.79^{*}$ & $44.83 \pm 6.88$ & $38.5 \pm 4.14^{*}$ & $47.67 \pm 7.15$ & $36.83 \pm 4.4^{*}$ & $43.5 \pm 5.32$ \\
\hline Fibrinogen [mg/dl] & $254.17 \pm 51.33$ & $226.83 \pm 23.79$ & $173.8 \pm 31.3^{+}$ & $224.33 \pm 21.94^{*}$ & $147.33 \pm 30.74$ & $215.17 \pm 25.56^{*}$ & $143.67 \pm 16.46$ & $240.17 \pm 20.47^{*}$ & $170 \pm 17.12$ \\
\hline Antithrombin [\%] & $77.17 \pm 7.41$ & $68.83 \pm 7.78$ & $49.17 \pm 8.54^{+}$ & $64.67 \pm 3.98^{*}$ & $38.17 \pm 7.25$ & $67.17 \pm 3.31^{*}$ & $38.33 \pm 6.12$ & $63.17 \pm 3.43^{*}$ & $41.33 \pm 3.27$ \\
\hline Factor II [\%] & $82.33 \pm 8.33$ & $76.33 \pm 4.23$ & $55.17 \pm 7.19^{+}$ & $74 \pm 5.48^{*}$ & $46.33 \pm 8.71$ & $68.5 \pm 8.07^{*}$ & $43.83 \pm 9.7$ & $63.17 \pm 5.34$ & $45.67 \pm 5.54$ \\
\hline Factor V [\%] & $81.17 \pm 7.41$ & $72.67 \pm 6.89$ & $53 \pm 10.1^{+}$ & $57.33 \pm 4.41^{*}$ & $34.5 \pm 6.25$ & $58.67 \pm 3.72^{*}$ & $35.83 \pm 2.64$ & $56.33 \pm 6.98^{*}$ & $40.33 \pm 5.09$ \\
\hline Factor VII [\%] & $73.67 \pm 11.33$ & $79.83 \pm 10.46^{*}$ & $56.33 \pm 7.76$ & $67.17 \pm 9.15^{*}$ & $42 \pm 9.27$ & $64.67 \pm 9.67^{*}$ & $41.33 \pm 8.31$ & $61.17 \pm 11.41^{*}$ & $45 \pm 9.92$ \\
\hline Factor VIII [\%] & $95.33 \pm 29.12$ & $83.75 \pm 13.35$ & $57.83 \pm 10.8^{+}$ & $71.8 \pm 9.88^{*}$ & $46.17 \pm 16.55$ & $53.83 \pm 11.2^{*}$ & $39.17 \pm 8.8$ & $71.67 \pm 30.94$ & $53.33 \pm 23.89$ \\
\hline Factor IX [\%] & $89 \pm 8.2$ & $95 \pm 5.22^{*}$ & $70.67 \pm 8.62$ & $87 \pm 5.33^{*}$ & $54.5 \pm 10.56$ & $74.5 \pm 10.91^{*}$ & $51.17 \pm 11.36$ & $77.33 \pm 16.37^{*}$ & $50.67 \pm 9.14$ \\
\hline Factor X [\%] & $73.5 \pm 9.09$ & $79.33 \pm 5.92^{*}$ & $54.17 \pm 5.88$ & $72.33 \pm 8.24^{*}$ & $48.83 \pm 6.68$ & $68.67 \pm 13.98^{*}$ & $44.17 \pm 11.07$ & $71.17 \pm 10.82^{*}$ & $49.83 \pm 10.38$ \\
\hline Factor XI [\%] & $83.8 \pm 29.8$ & $96 \pm 15.3^{*}$ & $71.67 \pm 6.35$ & $91.83 \pm 18.8$ & $72.83 \pm 33.88$ & $72.67 \pm 15.07^{*}$ & $49.5 \pm 12.32$ & $66.5 \pm 11.78^{*}$ & $48.17 \pm 8.33$ \\
\hline Factor XII activity [\%] & $86.17 \pm 28.27$ & $75.67 \pm 9.14^{*}$ & $54.67 \pm 8.26^{+}$ & $88 \pm 10.1^{*}$ & $48.33 \pm 13.85$ & $76.5 \pm 22.73^{*}$ & $50.17 \pm 20.44$ & $69.67 \pm 16.01^{*}$ & $48.33 \pm 9.42$ \\
\hline Factor XIII [\%] & $115.67 \pm 11.18$ & $100.67 \pm 12.4$ & $77.17 \pm 10.67^{+}$ & $97.5 \pm 11.71^{*}$ & $67.17 \pm 16.04$ & $86.33 \pm 6.38^{*}$ & $65.5 \pm 4.09$ & $92.17 \pm 19.05^{*}$ & $61 \pm 1.79$ \\
\hline Protein C activity [\%] & $71.67 \pm 13.98$ & $70.33 \pm 5.96^{*}$ & $50.5 \pm 4.97^{+}$ & $70.67 \pm 7.42^{*}$ & $41.33 \pm 8.36$ & $60.67 \pm 6.74^{*}$ & $37.33 \pm 7.26$ & $63.67 \pm 5.16^{*}$ & $48.17 \pm 6.97$ \\
\hline Protein S activity [\%] & $89.17 \pm 16.93$ & $60.33 \pm 7.12$ & $43.17 \pm 11.41^{+}$ & $33 \pm 4.34^{*}$ & $21.17 \pm 8.82$ & $55 \pm 8.12^{*}$ & $33.33 \pm 7.39$ & $43.8 \pm 15.42$ & $28.83 \pm 12.24$ \\
\hline v. Willebr. activation [\%] & $128.83 \pm 39.78$ & $97 \pm 19.01$ & $72.2 \pm 15.9^{+}$ & $98.67 \pm 18.35^{*}$ & $67.17 \pm 23.04$ & $67.5 \pm 26.61$ & $46 \pm 14.56$ & $82.33 \pm 28.11$ & $60.17 \pm 22.11$ \\
\hline v. Willebr. antigen [\%] & $141.83 \pm 45.28$ & $112.67 \pm 27.81$ & $77.2 \pm 17.08^{+}$ & $114.83 \pm 27.69^{*}$ & $71.67 \pm 22.17$ & $78 \pm 25.87$ & $53.17 \pm 17.68$ & $107.83 \pm 39.91$ & $76.5 \pm 28.74$ \\
\hline
\end{tabular}


Table 2 Significant age-specific differences at day one, four, 14, and 24

\begin{tabular}{|c|c|c|c|c|c|c|c|c|}
\hline \multirow[t]{2}{*}{ Parameter } & \multicolumn{4}{|l|}{$1: 1: 1$} & \multicolumn{4}{|l|}{ 3:1:1 } \\
\hline & Day 1 & Day 4 & Day 14 & Day 24 & Day 1 & Day 4 & Day 14 & Day 24 \\
\hline $\begin{array}{l}\text { ukocytes } \\
\left.10^{3} / \mu \mathrm{l}\right]\end{array}$ & $0.25 \pm 0.05^{c}$ & $0.37 \pm 0.08$ & $0.35 \pm 0.1$ & $0.45 \pm 0.1$ & $0.33 \pm 0.1$ & $0.33 \pm 0.14$ & $0.25 \pm 0.08$ & $0.5 \pm 0.18$ \\
\hline $\mathrm{pH}$ & $7.04 \pm 0.04^{b, c}$ & $7.03 \pm 0.05^{e}$ & $6.91 \pm 0.08$ & $6.89 \pm 0.03$ & $6.95 \pm 0.05^{b, c}$ & $6.9 \pm 0.04^{e}$ & $6.76 \pm 0.03$ & $6.69 \pm 0.06$ \\
\hline Sodium [mM] & $142.62 \pm 6.15^{c}$ & $140.48 \pm 1.63^{e}$ & $138.67 \pm 0.81$ & $137.42 \pm 0.99$ & $145.37 \pm 5.14^{\mathrm{b}, c}$ & $142.3 \pm 0.89^{e}$ & $138.43 \pm 2.09$ & $136.72 \pm 1.67$ \\
\hline Dtassium [mM] & $3.12 \pm 0.38^{b, c}$ & $3.91 \pm 0.38^{e}$ & $6.72 \pm 1.3$ & $7.45 \pm 0.48$ & $2.83 \pm 0.78^{b, c}$ & $4.69 \pm 0.35^{e}$ & $9.19 \pm 0.95$ & $13.01 \pm 0.15$ \\
\hline INTEM CT [s] & $204.83 \pm 13.6^{c}$ & $229.33 \pm 28.51$ & $243.5 \pm 121.51$ & $284.33 \pm 67.57$ & $206.83 \pm 16.46$ & $200.83 \pm 14.93^{\mathrm{e}}$ & $245 \pm 84.52$ & $259.83 \pm 25.86$ \\
\hline FIBTEM CT [s] & $57.83 \pm 10.65$ & $108.33 \pm 91.24$ & $69.5 \pm 38.9$ & $46.17 \pm 29.17$ & $84.33 \pm 15.72^{c}$ & $52.33 \pm 26.24$ & $132.33 \pm 107.69$ & $45.17 \pm 19.09$ \\
\hline INR & $1.03 \pm 0.05^{c}$ & $1.13 \pm 0.05$ & $1.12 \pm 0.04$ & $1.17 \pm 0.08$ & $1.23 \pm 0.08 b$ & $1.52 \pm 0.25$ & $1.53 \pm 0.15$ & $1.45 \pm 0.14$ \\
\hline Factor II [\%] & $76.33 \pm 4.23^{c}$ & $74 \pm 5.48$ & $68.5 \pm 8.07$ & $63.17 \pm 5.34$ & $55.17 \pm 7.19$ & $46.33 \pm 8.71$ & $43.83 \pm 9.7$ & $45.67 \pm 5.54$ \\
\hline actor V [\%] & $72.67 \pm 6.89^{\mathrm{a}, \mathrm{c}}$ & $57.33 \pm 4.41$ & $58.67 \pm 3.72$ & $56.33 \pm 6.98$ & $53 \pm 10.1^{a, b}$ & $34.5 \pm 6.25$ & $35.83 \pm 2.64$ & $40.33 \pm 5.09$ \\
\hline Factor VII [\%] & $79.83 \pm 10.46^{c}$ & $67.17 \pm 9.15$ & $64.67 \pm 9.67$ & $61.17 \pm 11.41$ & $56.33 \pm 7.76$ & $42 \pm 9.27$ & $41.33 \pm 8.31$ & $45 \pm 9.92$ \\
\hline Factor IX [\%] & $95 \pm 5.22^{b}$ & $87 \pm 5.33$ & $74.5 \pm 10.91$ & $77.3 \pm 16.37$ & $70.67 \pm 8.62^{c}$ & $54.5 \pm 10.56$ & $51.17 \pm 11.36$ & $50.67 \pm 9.14$ \\
\hline actor XI [\%] & $96 \pm 15.3$ & $91.83 \pm 18.8$ & $72.67 \pm 15.07$ & $66.5 \pm 11.78$ & $71.67 \pm 6.35^{b, c}$ & $72.83 \pm 33.88$ & $49.5 \pm 12.32$ & $48.17 \pm 8.33$ \\
\hline Factor XIII [\%] & $100.67 \pm 12.4$ & $97.5 \pm 11.71$ & $86.33 \pm 6.38$ & $92.17 \pm 19.05$ & $77.17 \pm 10.67^{c}$ & $67.17 \pm 16.04$ & $65.5 \pm 4.09$ & $61 \pm 1.79$ \\
\hline $\begin{array}{l}\text { Protein C } \\
\text { activity [\%] }\end{array}$ & $70.33 \pm 5.96$ & $70.67 \pm 7.42$ & $60.67 \pm 6.74$ & $63.67 \pm 5.16$ & $50.5 \pm 4.97^{b}$ & $41.33 \pm 8.36$ & $37.33 \pm 7.26$ & $48.17 \pm 6.97$ \\
\hline $\begin{array}{l}\text { Protein S } \\
\text { activity [\%] }\end{array}$ & $60.33 \pm 7.12^{b}$ & $33 \pm 4.34$ & $55 \pm 8.12$ & $43.83 \pm 15.42$ & $43.17 \pm 11.41^{a}$ & $21.17 \pm 8.82$ & $33.33 \pm 7.39$ & $28.83 \pm 12.24$ \\
\hline D-dimer $[\mu \mathrm{g} / \mathrm{l}]$ & $216.6 \pm 48.43^{b}$ & $239.5 \pm 43.98^{d}$ & $123 \pm 26.78$ & $156 \pm 50.45$ & $185.2 \pm 36.64$ & $180.67 \pm 37.6$ & $119.5 \pm 17.04$ & $150.5 \pm 32.44$ \\
\hline
\end{tabular}

Values are represented as mean \pm standard deviation. Lowercases indicate significant differences $(p<0.05)$ between: a - day 1 and 4 , b - day 1 and $14, \mathrm{c}-$ day 1 and $24, \mathrm{~d}$ - day 4 and 14 , e - day 4 and 24, and f - day 14 and 24, respectively.

reached significant levels with the exception of PTT at day one (Table 1). Furthermore, the INR trended to increase with age in both ratios. A declined functionality of the extrinsic and intrinsic system was also measured by ROTEM analysis. The CFT significantly decelerated at almost all time points in the 3:1:1 group of the EXTEM approach (Table 1). Similarly, CTs were prolonged by trend in the 3:1:1 group, however, not reaching significant level. Also the $\alpha$-angle and the clot amplitudes after 10 and 30 minutes declined in the 3:1:1 ratio at day one, four and 14 (Figure 4).

For the INTEM, FIBTEM and APTEM assays the main difference were observed after four and 14 days (Table 1, Figure 4). Thereafter mostly tendencies were determined due to a high variation within the groups. However, the MCF seemed to be the most consistent value in these three approaches providing significant declines in the 3:1:1 ratio irrespective of the activation pathway. As observed for other measured values the age differences were inconsistent and being present for few comparisons of EXTEM $\alpha$-angle as well as for INTEM and FIBTEM CTs (Table 2).

\section{Discussion}

\section{The ratio concept}

Over 10 years ago the correlation of transfusion practices and patients' outcome was stronger focused in trauma research. Several publications $[2,10,11,30]$ underlined the superiority for using defined ratios of pRBCs and FFPs solely or combined with PLTs. Due to heterogeneity such as patients' inclusion criteria (if they were even defined) and in the applied ratios (1:1; 2:1, 3:1 etc.) the evidence of these studies was limited. In 2007, Borgman et al. [2] firstly presented a systematic analysis of trauma care including a transfusion ratio concept that increased the survival rate in major bleeding patients. This study still represents the unproven guideline in handling these kinds of seriously injured patients. Currently, the multicenter PROPPR study systematically compared the transfusion ratios 1:1:1 and 2:1:1 (pRBCs:FFP:PLTs) in a clinical trial and brought first (but final) evidence in the discussion regarding transfusion ratios [31].

In this in vitro study the physiological characteristics of the 3:1:1 ratio go along with a reduction of all coagulation factors resulting in a lowered hemostasiological potential that was indicated by elevated INR and viscoelastic tests. The thrombelastometric findings (ROTEM) in dilution effects in the 3:1:1 ratio became evident by a decreased dynamic clot formation and clot quality as indicated by a flattened $\alpha$-angle and a lowered clot firmness after 10 and 30 minutes (A10, MCF). Furthermore, a trend of decelerated clot formation could be observed.

There was no evidence that the processing of plasma (freezing, storage, thawing) may explain the changes in 


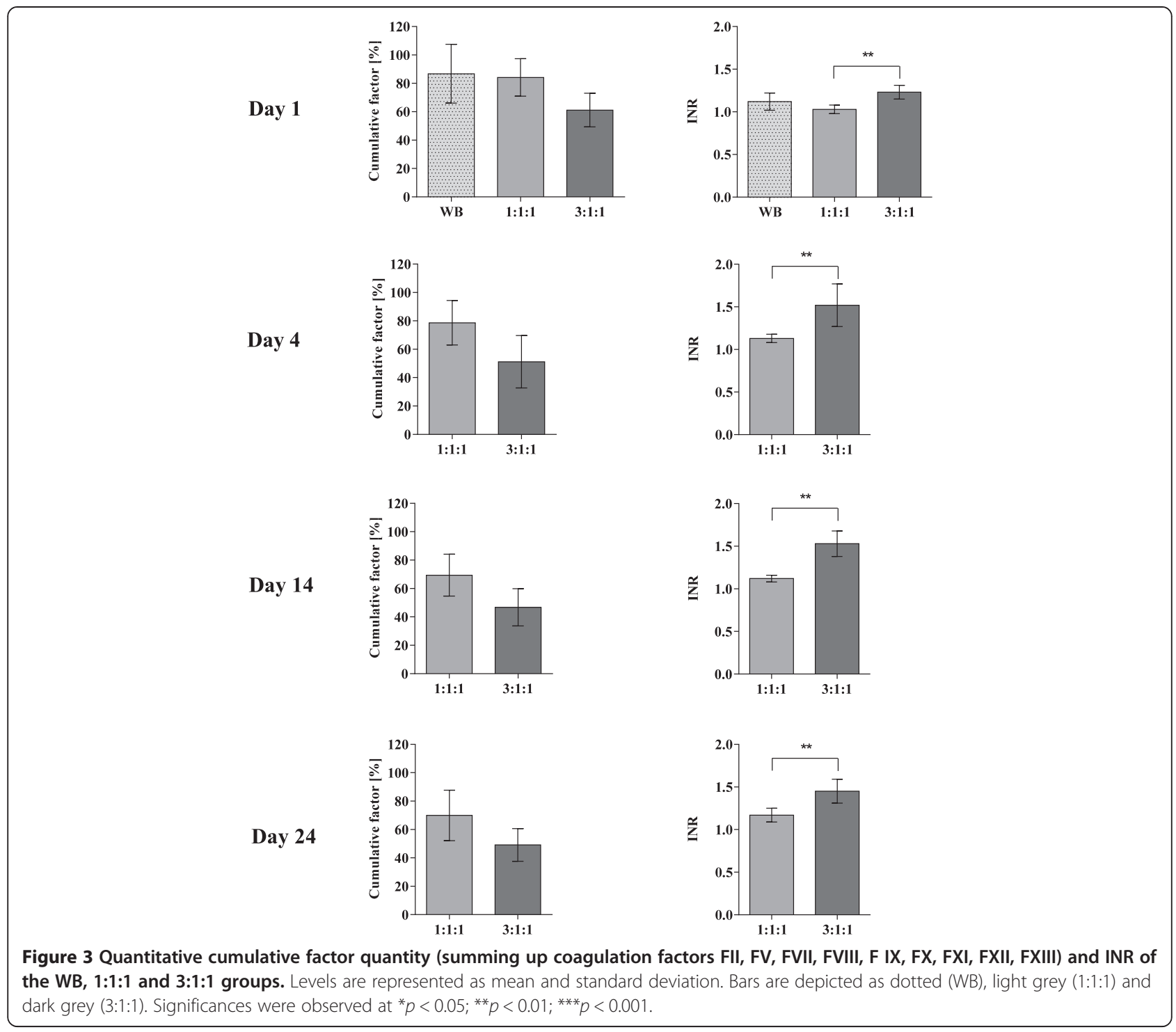

factor quantity and viscoelastic functionality of the 3:1:1 group, since 10 days of storage and subsequent thawing did not affect coagulation factors as shown previously [32]. In addition, this proceeding effect would have been observed in the 1:1:1 ratio as well. To ensure the allocation of functional factors in FFPs and to further minimize influencing effects on coagulation, maximum 4 days old factor-rich plasma was used at any time point before reconstitution. Thus, the lower quantity of coagulation factors whether significantly reduced in the 3:1:1 ratio or trend to be decreased can rather be explained by diluting effects than by inactivation of factors. Furthermore, cumulative factors were comparable between WB and 1:1:1 providing an adequate initial basis for coagulation [30,33]. In summary the hemostasiological potential of the 1:1:1 ratio rather referred to that of WB. Transfusion ratios leading to a nearly physiological hemostasiological potential and an effective coagulation may reduce the amount of pRBCs being transfused. According to the current European guideline [34] transfusion of $\mathrm{pRBC}$ is recommended in patients with $\mathrm{Hb}$ values below $7 \mathrm{mg} / \mathrm{dl}$.

The findings of the present study were in line with results of a recently published in vitro study in which a dilution effect in a 3:1 (pRBC:FFP) ratio was determined by simulating postpartum hemodilutional coagulopathy [35]. Therefore, there seemed to be a superiority of the 1:1 ratio of pRBC and FFP transfusion optimized by an additional application of the same ratio of PLTs. Interestingly, no dilution effect due to FFP was observed though not only concentrates of clotting factors were used. Similar results were reported for a thrombelastography (TEG) approach in which different ratios of pRBC:FFP: PTL were analyzed in vitro. In line with the results of the present study, a higher proportion of pRBCs such as 


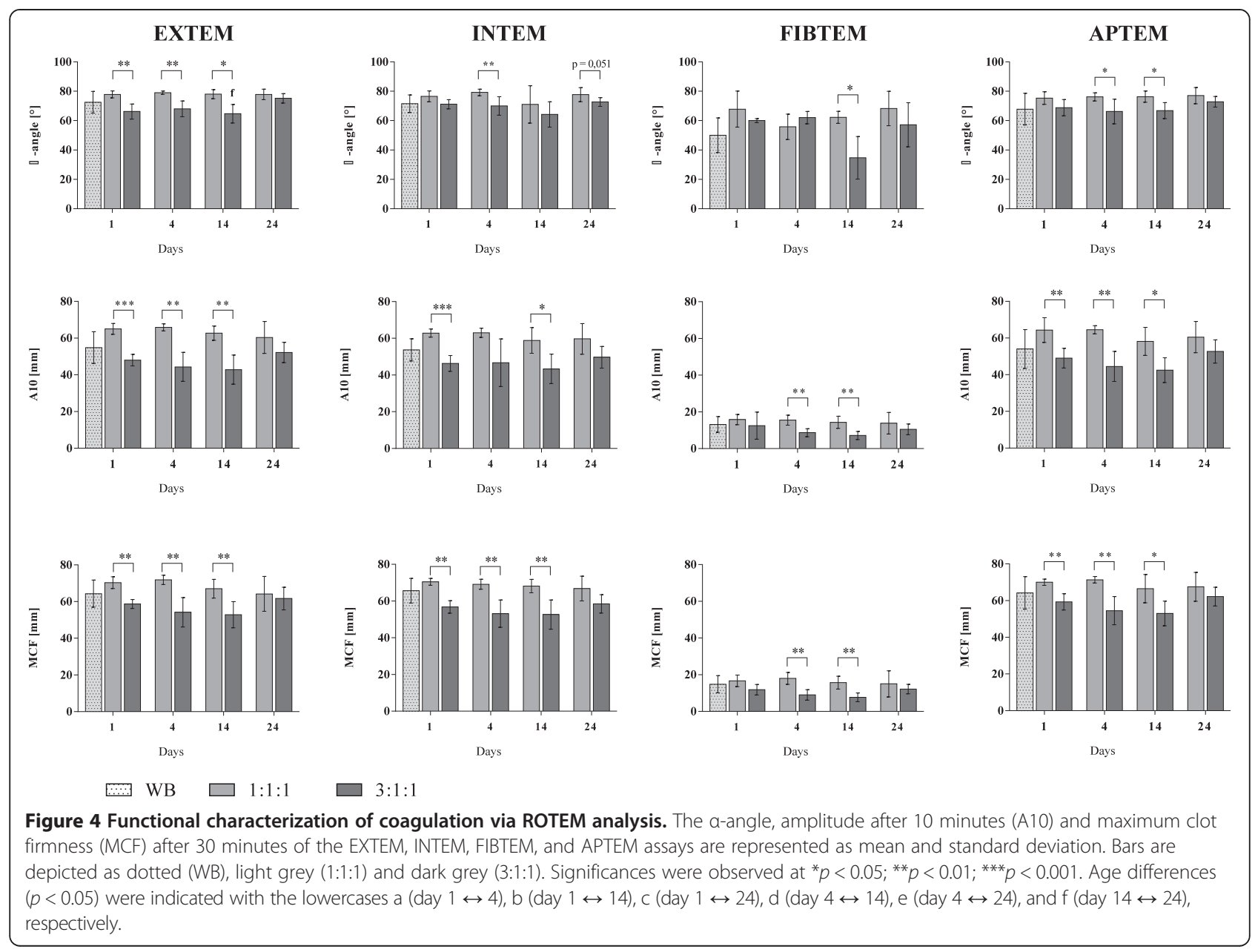

8:4:1 of pRBC:FFP:PTLs resulted in decreased abilities to form a stable clot (reduced angle and maximal amplitude) [36].

This in vitro experiment enabled the assessment of quantitative and functional coagulation under standardized environments and revealed main findings in dilution and associated effects on functional coagulation. However, interrelated physiological impact on TIC like hypothermia, acidosis, inflammation, shock or the preliminary treatments such as pre-hospital volume administration [37-39] and therefore, dilution and hyperpermeability, shedding of the endothelial glycocalyx with autoheparinization [40] and activation of the protein $C$ pathway $[41,42]$ influence its coagulation potency. Disease pattern leading to major bleeding are very individual. Therefore, we could only propose a possible influence of the applied ratio of blood products in human. Efficient therapy of coagulopathy reduces significantly morbidity and mortality in trauma patients $[2,43]$. Independent from (surgical) therapies, coagulopathy is recognized as independent disease with an individual need for therapy nowadays $[44,45]$.

\section{Age of blood products}

Addressing the question if there are differences in newer compared to older blood trends of reduced corpuscular components after 24 days were shown. Inverse the highest potassium and lowest $\mathrm{pH}$ value were measured at day 24 which might be explained by an increasing erythrocytes degradation [46]. With regard to clinical practice one should consider that potassium levels higher than $8 \mathrm{mmol} / \mathrm{l}$ have to be taken into further account when applying the 3:1:1 ratio. As demonstrated in previous clinical studies $[27-29,47,48]$ in which the length of storage of pRBC influenced hemolysis, changes in deformability as well as osmotic fragility the results of this study did not reveal any continuous age effect according to the hemostasiological potential. However, the changes of potassium $(13.01 \pm 0.15 \mathrm{mM})$, sodium $(136.72 \pm 1.67 \mathrm{mM})$ and $\mathrm{pH}$ levels $(6.69 \pm 0.06)$ associated with aging blood products cannot be disregarded when applying to patients after 24 days of storage.

Regarding clotting time and clot formation a continuous but not significant increase was detected for INTEM while FIBTEM values reacted vice versa. 


\section{Conclusions}

This systematic in vitro study offers valuable information about transfusion ratios as well as influencing age effects on coagulation. With regard to limitations of in vitro trials, the presented results suggest a superiority of 1:1:1 ratio in a physiological setting in case of transfusion encouraging higher use of plasma rather than pRBCs. Thus, dosage, ratio and administration of blood components still remain a dichotomy between benefits and harms whereby this study highlighted the need for multi-center clinical trials to determine the optimal transfusion strategy.

\section{Key messages}

- The higher proportion of pRBCs of the 3:1:1 ratio resulted in dilution properties of almost all coagulation factors and inhibitors.

- Dilution likewise affected the hemostasiological potential which was indicated by an elevated PTT and INR in the 3:1:1 compared to 1:1:1 group.

- The reduced functional coagulation of the 3:1:1 ratio was further specified by a decelerated CFT, flattened $\alpha$-angle and diminished MCF of the ROTEM analysis.

\begin{abstract}
Abbreviations
ACT: Activated clotting time; APTT: Activated partial thromboplastin time; BGA: Blood gas analysis; CFT: Clot formation time; Functional fibrinogen: Tissue factor-activated thromboelastography including a platelet inhibitor; FBC: Full blood count; FFP: Fresh frozen plasma; INR: International normalized ratio; MA: Maximum amplitude; MCF: Maximum clot firmness; MTP(s): Massive transfusion protocol(s); PLT(s): Platelet concentrate(s); pRBCs: packed red blood cells; TEG: Thromboelastography; WB: Whole blood.
\end{abstract}

\section{Competing interests}

The authors declare that they have no competing interests.

\section{Authors' contributions}

$\mathrm{AD}$ and NS contributed to study conception and study design, collection of data, interpretation and preparation of the manuscript. ES and MM contributed to study conception and study design, analysis and interpretation of data and revision of the manuscript. UB, SK and CFD contributed to study design and revision of the article. All authors have read and approved the manuscript for publication.

\section{Acknowledgement}

We kindly thank M. Lassonczyk and A. Camphausen for technical support.

\footnotetext{
Author details

${ }^{1}$ Institute for Research in Operative Medicine, Faculty of Health, Department of Medicine, Witten/Herdecke University, Ostmerheimer Str. 200, D-51109 Cologne, Germany. ${ }^{2}$ Department of Traumatology, Orthopaedic Surgery and Sports Traumatology, Cologne-Merheim Medical Centre (CMMC), Witten/ Herdecke University, Campus Cologne-Merheim, Ostmerheimer Str. 200, D-51109 Cologne, Germany. ${ }^{3}$ Institute of Transfusion Medicine Cologne-Merheim Medical Centre (CMMC), Witten/Herdecke University, Campus Cologne-Merheim, Cologne (Germany), Ostmerheimer Str. 200, D-51109 Cologne, Germany.
}

Received: 9 September 2014 Accepted: 16 December 2014

Published online: 09 January 2015

\section{References}

1. Curry N, Stanworth S, Hopewell S, Dorée C, Brohi K, Hyde C. Traumainduced coagulopathy-a review of the systematic reviews: is there sufficient evidence to guide clinical transfusion practice? Transfus Med Rev. 2011;25:217-31. e2.

2. Borgman MA, Spinella PC, Perkins JG, Grathwohl KW, Repine T, Beekley AC, et al. The ratio of blood products transfused affects mortality in patients receiving massive transfusions at a combat support hospital. J Trauma. 2007:63:805-13.

3. Gunter OL, Au BK, Isbell JM, Mowery NT, Young PP, Cotton BA. Optimizing outcomes in damage control resuscitation: identifying blood product ratios associated with improved survival. J Trauma. 2008;65:527-34.

4. Hoyt DB, Dutton RP, Hauser CJ, Hess JR, Holcomb JB, Kluger Y, et al. Management of coagulopathy in the patients with multiple injuries: results from an international survey of clinical practice. J Trauma. 2008;65:755-64. discussion 764-5.

5. Young PP, Cotton BA, Goodnough LT. Massive transfusion protocols for patients with substantial hemorrhage. Transfus Med Rev. 2011;25:293-303.

6. Levi M, Fries D, Gombotz H, van der Linden P, Nascimento B, Callum JL, et al. Prevention and treatment of coagulopathy in patients receiving massive transfusions. Vox Sang. 2011;101:154-74.

7. Lier H, Krep H, Schroeder S, Stuber F. Preconditions of hemostasis in trauma: a review. The influence of acidosis, hypocalcemia, anemia, and hypothermia on functional hemostasis in trauma. J Trauma. 2008;65:951-60.

8. Cushing M, Shaz BH. Blood transfusion in trauma patients: unresolved questions. Minerva Anestesiol. 2011;77:349-59.

9. Stahel PF, Moore EE, Schreier SL, Flierl MA, Kashuk JL. Transfusion strategies in postinjury coagulopathy. Curr Opin Anaesthesiol. 2009:22:289-98.

10. Johansson PI, Stensballe J. Hemostatic resuscitation for massive bleeding: the paradigm of plasma and platelets-a review of the current literature. Transfusion. 2010;50:701-10.

11. Phan HH, Wisner DH. Should we increase the ratio of plasma/platelets to red blood cells in massive transfusion: what is the evidence? Vox Sang. 2010;98(3 Pt 2):395-402.

12. Maegele M, Lefering R, Paffrath T, Tjardes T, Simanski C, Bouillon B. Redblood-cell to plasma ratios transfused during massive transfusion are associated with mortality in severe multiple injury: a retrospective analysis from the Trauma Registry of the Deutsche Gesellschaft für Unfallchirurgie. Vox Sang. 2008;95:112-9.

13. Kozek-Langenecker S, Sørensen B, Hess JR, Spahn DR. Clinical effectiveness of fresh frozen plasma compared with fibrinogen concentrate: a systematic review. Crit Care. 2011;15:R239.

14. Lier H, Böttiger BW, Hinkelbein J, Krep H, Bernhard M. Coagulation management in multiple trauma: a systematic review. Intensive Care Med. 2011;37:572-82.

15. Rajasekhar A, Gowing R, Zarychanski R, Arnold DM, Lim W, Crowther MA, et al. Survival of trauma patients after massive red blood cell transfusion using a high or low red blood cell to plasma transfusion ratio. Crit Care Med. 2011;39:1507-13.

16. Murad MH, Stubbs JR, Gandhi MJ, Wang AT, Paul A, Erwin PJ, et al. The effect of plasma transfusion on morbidity and mortality: a systematic review and meta-analysis. Transfusion. 2010;50:1370-83.

17. Koch CG, Li L, Sessler DI, Figueroa P, Hoeltge GA, Mihaljevic T, et al. Duration of red-cell storage and complications after cardiac surgery. N Engl J Med. 2008;358:1229-39.

18. Tung J-P, Fraser JF, Nataatmadja M, Colebourne KI, Barnett AG, Glenister KM, et al. Age of blood and recipient factors determine the severity of transfusion-related acute lung injury (TRALI). Crit Care. 2012;16:R19.

19. Solomon SB, Wang D, Sun J, Kanias T, Feng J, Helms CC, et al. Mortality increases after massive exchange transfusion with older stored blood in canines with experimental pneumonia. Blood. 2013;121:1663-72.

20. Inaba K, Branco BC, Rhee P, Blackbourne LH, Holcomb JB, Spinella PC, et al. Impact of the duration of platelet storage in critically ill trauma patients. J Trauma. 2011;71:1766-73. discussion 1773-4.

21. Spinella PC, Carroll CL, Staff I, Gross R, Mc Quay J, Keibel L, et al. Duration of red blood cell storage is associated with increased incidence of deep vein thrombosis and in hospital mortality in patients with traumatic injuries. Crit Care. 2009;13:R151 
22. Weinberg JA, McGwin G, Griffin RL, Huynh VQ, Cherry SA, Marques MB, et al. Age of transfused blood: an independent predictor of mortality despite universal leukoreduction. J Trauma. 2008;65:279-82. discussion 282-4.

23. Wang D, Sun J, Solomon SB, Klein HG, Natanson C. Transfusion of older stored blood and risk of death: a meta-analysis. Transfusion. 2012;52:1184-95.

24. Leal-Noval SR, Muñoz-Gómez M, Arellano-Orden V, Marín-Caballos A Amaya-Villar R, Marín A, et al. Impact of age of transfused blood on cerebral oxygenation in male patients with severe traumatic brain injury. Crit Care Med. 2008;36:1290-6.

25. Frank SM, Abazyan B, Ono M, Hogue CW, Cohen DB, Berkowitz DE, et al. Decreased erythrocyte deformability after transfusion and the effects of erythrocyte storage duration. Anesth Analg. 2013;116:975-81.

26. Tinmouth A, Chin-Yee I. The clinical consequences of the red cell storage lesion. Transfus Med Rev. 2001;15:91-107.

27. Simak J, Gelderman MP. Cell membrane microparticles in blood and blood products: potentially pathogenic agents and diagnostic markers. Transfus Med Rev. 2006;20:1-26.

28. Holovati JL, Wong KA, Webster JM, Acker JP. The effects of cryopreservation on red blood cell microvesiculation, phosphatidylserine externalization, and CD47 expression. Transfusion. 2008;48:1658-68.

29. Almizraq R, Tchir JDR, Holovati JL, Acker JP. Storage of red blood cells affects membrane composition, microvesiculation, and in vitro quality. Transfusion. 2013;53:2258-67.

30. Gonzalez EA, Moore FA, Holcomb JB, Miller CC, Kozar RA, Todd SR, et al. Fresh frozen plasma should be given earlier to patients requiring massive transfusion. J Trauma. 2007:62:112-9.

31. Baraniuk S, Tilley BC, del Junco DJ, Fox EE, van Belle G, Wade CE, et al. Pragmatic Randomized Optimal Platelet and Plasma Ratios (PROPPR) Trial: Design, rationale and implementation. Injury. 2014;45:1287-95.

32. Tholpady A, Monson J, Radovancevic R, Klein K, Bracey A. Analysis of prolonged storage on coagulation Factor $(F) V, F V I I$, and FVIII in thawed plasma: is it time to extend the expiration date beyond 5 days? Transfusion. 2013;53:645-50.

33. Armand R, Hess JR. Treating coagulopathy in trauma patients. Transfus Med Rev. 2003;17:223-31.

34. Spahn DR, Bouillon B, Cerny V, Coats TJ, Duranteau J, Fernández-Mondéjar E, et al. Management of bleeding and coagulopathy following major trauma: an updated European guideline. Crit Care. 2013;17:R76.

35. Farber MK, Sadana N, Kaufman RM, Liu X, Kodali BS. Transfusion ratios for postpartum hemodilutional coagulopathy: an in vitro thromboelastographic model. Am J Obstet Gynecol. 2014;210:323. e1-7.

36. Agren A, Edgren G, Kardell M, Ostlund A, Wikman AT. In vitro combinations of red blood cell, plasma and platelet components evaluated by thromboelastography. Blood Transfus. 2014;12:491-6.

37. Wafaisade A, Wutzler S, Lefering R, Tjardes T, Banerjee M, Paffrath T, et al. MMTR of D: Drivers of acute coagulopathy after severe trauma: a multivariate analysis of 1987 patients. Emerg Med J. 2010;27:934-9.

38. Meng ZH, Wolberg AS, Monroe DM, Hoffman M. The effect of temperature and $\mathrm{pH}$ on the activity of factor VIla: implications for the efficacy of highdose factor VIla in hypothermic and acidotic patients. J Trauma. 2003;55:886-91.

39. Engström M, Schött U, Romner B, Reinstrup P. Acidosis impairs the coagulation: A thromboelastographic study. J Trauma. 2006;61:624-8.

40. Ostrowski SR, Johansson PI. Endothelial glycocalyx degradation induces endogenous heparinization in patients with severe injury and early traumatic coagulopathy. J Trauma Acute Care Surg. 2012;73:60-6.

41. Brohi K, Cohen MJ, Ganter MT, Matthay MA, Mackersie RC, Pittet J-F. Acute traumatic coagulopathy: initiated by hypoperfusion: modulated through the protein C pathway? Ann Surg. 2007;245:812-8.

42. Brohi K, Cohen MJ, Davenport RA. Acute coagulopathy of trauma: mechanism, identification and effect. Curr Opin Crit Care. 2007;13:680-5.

43. Hess JR. Resuscitation of trauma-induced coagulopathy. Hematology Am Soc Hematol Educ Program. 2013;2013:664-7.

44. Cohen MJ. Acute traumatic coagulopathy: Clinical characterization and mechanistic investigation. Thromb Res. 2014;133(Suppl):S25-7.

45. Maegele M, Schöchl H, Cohen MJ. An update on the coagulopathy of trauma. Shock. 2014;41 Suppl 1:21-5.
46. Ozment CP, Mamo LB, Campbell ML, Lokhnygina Y, Ghio AJ, Turi JL. Transfusion-related biologic effects and free hemoglobin, heme, and iron. Transfusion. 2013;53:732-40.

47. Sambasivan CN, Kunio NR, Nair PV, Zink KA, Michalek JE, Holcomb JB, et al. High ratios of plasma and platelets to packed red blood cells do not affect mortality in nonmassively transfused patients. J Trauma. 2011;71(2 Suppl 3):S329-36.

48. Tinmouth A, Fergusson D, Yee IC, Hébert PC. Clinical consequences of red cell storage in the critically ill. Transfusion. 2006;46:2014-27.

\section{Submit your next manuscript to BioMed Central and take full advantage of:}

- Convenient online submission

- Thorough peer review

- No space constraints or color figure charges

- Immediate publication on acceptance

- Inclusion in PubMed, CAS, Scopus and Google Scholar

- Research which is freely available for redistribution 